\title{
Association of Myopia with cognitive function among one million adolescents
}

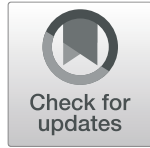

Jacob Megreli ${ }^{1,2}$, Adiel Barak ${ }^{3,4}$, Maxim Bez ${ }^{1}$, Dana Bez ${ }^{1,2}$ and Hagai Levine $2^{2^{*}}$

\begin{abstract}
Background: Myopia is a leading cause of visual impairment worldwide, and its increasing incidence is of public health concern. Cognitive function was associated with myopia among children, but evidence for adolescents is scarce. The purpose of this study was to determine whether myopia is associated with cognitive function, and which cognitive ability, verbal or non-verbal, is involved.

Methods: We conducted a population-based cross-sectional study of 1,022,425 Israeli candidates for military service aged 16.5-18 years. Participants underwent a comprehensive battery of tests assessing verbal and non-verbal intelligence, which yields a summarized cognitive function score (CFS). In addition, subjective visual acuity examination followed by objective non-cycloplegic refraction was carried out for each participant. Association between myopia and cognitive function was evaluated by multivariable logistic regression models adjusted for gender, age, country of origin, socioeconomic status, years of education, body mass index, height and year of examination.

Results: Compared to the intermediate CFS of the entire cohort, participants who had the highest CFS had 1.85fold $(95 \% \mathrm{Cl}, 1.81$ to $1.89 ; P<.001)$ higher odds of having myopia and 2.73 -fold $(95 \% \mathrm{Cl}, 2.58$ to $2.88 ; P<.001)$ higher odds of high myopia, while participants with the lowest CFS had 0.59 -fold ( $95 \% \mathrm{Cl}, 0.57$ to $0.61, P<.001$ ) lower odds of having myopia. The verbal components of the cognitive function assessment had stronger associations with myopia than the non-verbal components $(P<.001$, for all).
\end{abstract}

Conclusions: Cognitive function, especially verbal intelligence, is strongly and consistently associated with myopia among adolescents.

Keywords: Myopia, Cognition, Cross-sectional study

\section{Background}

Myopia is a functional and medical problem, and has become an emerging public health problem during the last several decades [1-4]. Myopia generally occurs as a result of axial elongation of the eyeball during childhood. It is currently estimated that nearly $23 \%$ of the world's population has myopia, a figure which is expected to double by 2050 [5]. Myopia, and especially high myopia, often results in serious problems that can lead to

\footnotetext{
* Correspondence: hagai.levine@gmail.com

${ }^{2}$ Hebrew University-Hadassah Faculty of Medicine, Braun School of Public Health and Community Medicine, P.O Box 12272, 9112002 Jerusalem, Israel Full list of author information is available at the end of the article
}

detrimental ramifications, including glaucoma, macular degeneration, detachment of retina, and cataract [6].

Myopia is a multifactorial disorder that is currently considered to be affected by both environmental and hereditary factors [7-9]. Cognitive function is one of the most arguable and investigated associations with myopia $[10,11]$. Some early works studying this association suggested that a pleiotropic relationship between high cognitive function and myopia may exist, whereby a single or a group of genes might be responsible for both traits [12]. While the mechanism of this association remains controversial, the majority of the studies exploring this association focused only on children, leading to a 
scarcity of literature among adolescents and young adults [10]. Only one study reported a significant association between myopia and cognitive performance in adults 40-79 years of age [13], while some studies found no statistically significant relationship between myopia and cognitive function [14-16].

The aim of this study was to examine the association between myopia and cognitive function, and the specific cognitive abilities involved - verbal and non-verbal, in order to direct further research on the development of myopia, its etiology, epidemiology and pathophysiology.

\section{Methods}

\section{Study design and population}

Israeli adolescents recruited for mandatory military service undergo a medical and cognitive assessment at mean age of 17 years. We performed a population-based cross-sectional study, based on the nationwide Israel Defense Forces (IDF) conscription registry from 1993 to 2012. We limited the study till 2012, as since 2013, the eligible population for assessment changed to include the ultra-Orthodox Jewish population, who have extremely high proportions of myopia (82\%) [17]. Total of
1,312,176 adolescents between 16.5 to 18 years of age were examined by the draft board (Fig. 1). We excluded 52, 077 recruits with missing refractive measurements; 2333 who had prior refractive surgery; 733 with keratoconus; 18 , 274 with missing cognitive assessment, socio-demographic or anthropometric information; 59,659 from a non-Jewish population, since they are largely exempt from military service with only a small fraction being called up for a medical evaluation, thereby these adolescents were not representative of the overall minority population [18]; 156,675 who were born abroad, since the tests assessing cognitive function are administrated only in Hebrew therefore it might create a language barrier, and because the prevalence of myopia varies across populations of different geographic regions [3]. These exclusions resulted in a study sample of 1 , 022,425 participants. This study was approved by the Institutional Ethics Committee of the Israel Defense Forces Medical Corps (Approval No. 1669-2016) and conformed to the tenets of the Declaration of Helsinki. Participants anonymity was preserved. Patient consent was waived as the raw data was deidentified. Authors had full access to the database of the IDF Medical Corps, located at the Surgeon General's headquarters in Ramat-Gan, Israel.

289,751 were excluded based on:

156,675 were born abroad

59,659 were non-Jewish minorities

52,077 had missing refractive data

18,274 had missing values*

2,333 had prior refractive surgery

733 had keratoconus

$1,022,425$ subjects were

included in the analysis

Fig. 1 Flow diagram of selected study population. *Missing values: cognitive function score: 4553 (0.4\%); country of origin: $7558(0.6 \%)$; socioeconomic status: 4927 (0.4\%); height: 384 (0.03\%); body mass index: 642 (0.1\%); years of education: 210 (0.02\%) 


\section{Visual acuity examination}

Visual acuity examination by a standard Snellen chart was carried out for each participant by a qualified technician. The candidate's unaided visual acuity was evaluated using a standard Snellen chart at $6 \mathrm{~m}$. All candidates with unaided visual acuity lower than $6 / 6 \mathrm{~m}$ underwent an objective non-cycloplegic refraction with an Autorefractometer (Speedy K; Nikon Corp., Tokyo, Japan; KR-8000, KR7000S and earlier models, Topcon, Tokyo, Japan) [19], followed by a complementary subjective refraction, for validation, using a standard Snellen chart. For each candidate, spherical equivalent (SEQ) was calculated separately for each eye according to the following formula: (SEQ $=$ sphere power $+[$ cylinder power/2]) [20]. Myopia was defined as SEQ of -0.50 diopter (D) or less. Low myopia was defined as an SEQ between -0.50 and $-2.99 \mathrm{D}$, moderate myopia was defined as an SEQ between -3.00 and $-5.99 \mathrm{D}$, and high myopia was defined as an SEQ of $-6.00 \mathrm{D}$ or less. The classification for each individual was made based on the worse SEQ between both eyes. Worse SEQ was chosen to be used for myopia definitions after preliminary analysis that demonstrated a satisfactory correlation between both eyes (Pearson correlation coefficient, 0.92) [21, 22].

\section{Cognitive assessment}

Participants underwent a comprehensive cognitive assessment by a battery of tests that yields a cognitive function score (CFS) [23]. The score is normally distributed in the population, ranging from one to nine, so an intermediate CFS of five was considered the reference group. CFS is considered a valid measure of general intelligence, and is highly correlated with the Wechsler Adult Intelligence Scale [23-25]. The battery of cognitive assessment tests was composed of four subtests: two subtests assessed verbal intelligence (similarities and verbal instructions tests), and two subtests assessed nonverbal intelligence (arithmetic and visual-spatial tests), as previously described by Rabinowitz et al. [25]. These four subtests were classified separately into eight percentile groups $(<5$ th: reference group; 5-10th; 10-25th; 25-50th; 50-75th; 75-90th; 90-95th; > 95th). In order to enable comparisons between the four subtests, they were also classified by median, with the lower half being the reference group.

\section{Covariates and study variables}

Socio-demographic and anthropometric data were recorded as part of the draft board intake process. Education was grouped according to number of years of formal schooling: $<9,10$ to 11 , and $\geq 12$ (which includes higher and academic studies). Socioeconomic status (SES) was determined according to the Israeli Ministry of Interior classification, based on city of residence [26], as low, medium or high. Place of origin was determined by the birthplace of the father or grandfather (if the father was Israeli-born), and categorized according to country of origin. Body mass index (BMI) was calculated as weight in kilograms divided by height in meters squared. BMI and height values were coded according to the age and sex adjusted growth charts of the United States Centers for Disease Control and Prevention (CDC) [27].

\section{Statistical analysis}

Univariable logistic regression models were used to evaluate the associations between myopia, as an outcome variable, to each of the dependent variables and covariates. The $x^{2}$ test was used for categorical variables, and 1 -way analysis of variance was used for continuous variables. The association between CFS and myopia was assessed using multivariable logistic regression models, adjusted for all predetermined covariates that were found to be statistically significant in the univariable regression models: age (continuous variable), gender, country of origin, SES, years of education, BMI, height, and year of examination (ordinal variable). Same multivariable regression models were used separately to estimate the association of the four cognitive assessment subtests to myopia. Two-sided $P<.001$ was considered statistically significant. Results of the regression models are reported as odds ratio (OR) with 95\% confidence interval $(95 \% \mathrm{CI})$. Analyses were performed using SPSS statistics for Windows version 22 (IBM, Armonk, NY, USA).

\section{Results}

Characteristics of the study participants are described in Table 1 . The mean age of the $1,022,425$ participants at the time of evaluation was $17.2 \pm 0.3$ years, 569,551 $(55.7 \%)$ of them were males, the majority had completed high school, and more than $50 \%$ were classified as medium socioeconomic status. The overall prevalence of myopia among the study participants was $32.2 \%$ : $19.9 \%$ had mild myopia, 9.4\% had moderate myopia, and $2.9 \%$ had high myopia. Myopia was more prevalent among females than males: $34.2 \%$ vs $30.6 \%$, respectively $(P<.001)$. Prevalence of myopia was lower among immigrants from Ethiopia (19.0\%). Both immigrants from Ethiopia and former USSR countries had large-scale immigration waves at more recent times compared to the rest of the population. There was a significant increase in the prevalence of myopia during the 20-year period of examination: from $26.9 \%$ in 1993 to $33 \%$ in $2012(P<.001$; eTable 1 in the Supplement). Univariable analysis showed that age, gender, country of origin, SES, years of education, BMI, height and year of examination were all associated with myopia $(P<.001)$. 
Table 1 Myopia Prevalence by Sociodemographic Variables, Univariable Logistic Regression Analysis

\begin{tabular}{|c|c|c|c|}
\hline Variable & & Adolescents with Myopia, No./Total No. (\%) & $\boldsymbol{P}$ Value \\
\hline \multirow[t]{2}{*}{ Gender } & Female & $154857 / 452874(34.2)$ & $<.001$ \\
\hline & Male & $174016 / 569551(30.6)$ & \\
\hline \multirow[t]{6}{*}{ Country of origin } & Western & $98543 / 296049(33.3)$ & $<.001$ \\
\hline & North-African & $81563 / 278154(29.3)$ & \\
\hline & Asia & $92034 / 268265(34.3)$ & \\
\hline & Former USSR & $26481 / 82488(32.1)$ & \\
\hline & Ethiopia & $1697 / 8927(19.0)$ & \\
\hline & Israel & 28555/88542 (32.3) & \\
\hline \multirow[t]{3}{*}{ Socioeconomic status $^{a}$} & Low & $81185 / 235072(34.5)$ & $<.001$ \\
\hline & Medium & $169265 / 546684(31.0)$ & \\
\hline & High & $78423 / 240669(32.6)$ & \\
\hline \multirow[t]{3}{*}{ Years of education } & $\leq 9$ & 2478/12793 (19.4) & $<.001$ \\
\hline & $10-11$ & $13632 / 53825(25.3)$ & \\
\hline & $\geq 12$ & $312763 / 955807(32.7)$ & \\
\hline \multirow[t]{4}{*}{$\mathrm{BMI}^{\mathrm{b}}$} & Underweight & $33874 / 100070(33.9)$ & $<.001$ \\
\hline & Normal weight & 250232/787254 (31.8) & \\
\hline & Overweight & $28127 / 86113(32.7)$ & \\
\hline & Obese & 16640/48988 (34.0) & \\
\hline \multirow[t]{3}{*}{ Height $^{c}$} & Short & 19128/54717 (35.0) & $<.001$ \\
\hline & Normal & 298836/934926 (32.0) & \\
\hline & Tall & 10909/32782 (33.3) & \\
\hline Total & & $328873 / 1022425(32.2)$ & \\
\hline
\end{tabular}

Abbreviations: USSR Union of Soviet Socialist Republics, BMI Body mass index

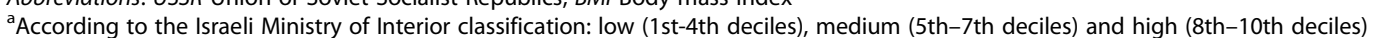

${ }^{\mathrm{b}}$ Body mass index. Sex- and Age- (by months) adjusted percentiles of BMI and height according to the United States Centers for Disease Control and Prevention (CDC) 2000 growth charts. BMI classification: underweight (BMI <5th percentile), normal weight (5th percentile $\leq$ BMI < 85th), overweight (85th percentile $\leq$ BMI < 95th), and obese (BMI > 95th percentile)

'Height classification: short (Height $<$ th percentile), normal (5th percentile $\leq$ Height $<95$ th), and tall (Height $\geq 95$ th percentile)

The prevalence of myopia increased gradually in accordance with CFS: from $21.7 \%$ among those with the lowest score to $43.3 \%$ among those with the highest score $(P<.001$; Table 2$)$. CFS was found to have a consistent positive association with myopia in univariable regression models. Following multivariable adjustment, the association between CFS and myopia remained consistent and became accentuated (Fig. 2). Compared to the intermediate CFS, participants with the highest CFS had 1.85-fold (95\% CI, 1.81 to $1.89 ; P<.001)$ higher odds

Table 2 Cognitive characteristics and association with myopia in univariable and multivariable models

\begin{tabular}{llll}
\hline CFS & Adolescents with Myopia, No./Total No. (\%) & Unadjusted OR (95\% Cl) & Adjusted OR $^{\mathbf{a}}(95 \%$ Cl) \\
\hline $\mathbf{1}$ & $4619 / 21319(21.7)$ & $0.61(0.59-0.63)$ & $0.59(0.57-0.61)$ \\
$\mathbf{2}$ & $10845 / 47825(22.7)$ & $0.65(0.64-0.67)$ & $0.61(0.61-0.64)$ \\
$\mathbf{3}$ & $25988 / 101698(25.6)$ & $0.76(0.75-0.77)$ & $0.72(0.72-0.74)$ \\
$\mathbf{4}$ & $47062 / 166015(28.3)$ & $0.87(0.86-0.89)$ & $0.85(0.84-0.87)$ \\
$\mathbf{5}$ & $65860 / 211885(31.1)$ & $1.00[$ Reference] & $1.18(1.17-1.20)$ \\
$\mathbf{6}$ & $69023 / 202101(34.2)$ & $1.14(1.14-1.17)$ & $1.36(1.34-1.38)$ \\
$\mathbf{7}$ & $53842 / 145595(37.0)$ & $1.30(1.28-1.32)$ & $1.56(1.54-1.59)$ \\
$\mathbf{8}$ & $32503 / 81779(39.7)$ & $1.46(1.44-1.49)$ & $1.85(1.81-1.89)$ \\
$\mathbf{9}$ & $19131 / 44208(43.3)$ & $1.69(1.66-1.73)$ &
\end{tabular}

OR Odds ratio, Cl Confidence interval, CFS Cognitive function score

${ }^{a}$ Adjusted odds ratio for age, gender, country of origin, socioeconomic status, years of education, BMl, height and year of examination by multivariable logistic regression model $P$ value was $<.001$ for all comparisons, both unadjusted and adjusted 


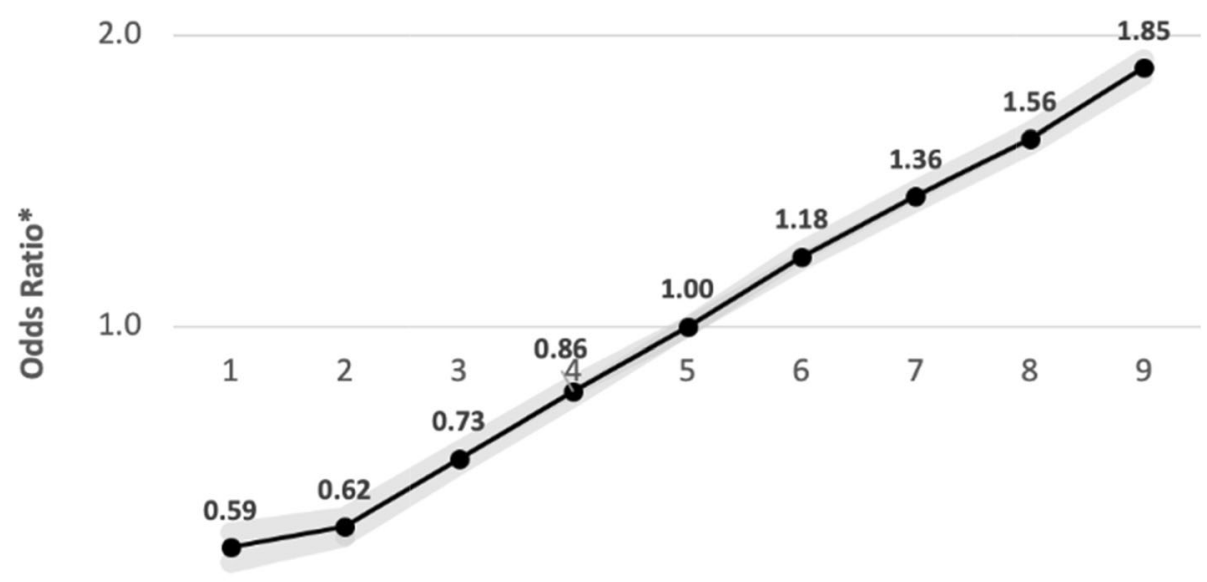

0.5

CFS

Fig. 2 Association of cognitive function score with myopia. Values represent the odds ratio for each CFS group in comparison with the intermediate CFS. Gray area represents the $95 \%$ confidence interval. Adjusted odds ratio for gender, age, country of origin, socioeconomic status, years of education, BMl, height and year of examination by multivariable logistic regression model. ${ }^{*} P<.001$ for all comparisons $(N=1,022,425)$

of having myopia, while participants with the lowest CFS had 0.59 -fold ( $95 \% \mathrm{CI}, 0.57$ to $0.61, P<.001$ ) lower odds of having myopia. Association between CFS and myopia remained consistent regardless of the severity of the myopia, and was found to be the strongest for moderate and high myopia (Fig. 3). In comparison with the intermediate CFS, participants who had the highest CFS had 1.54-fold (95\% CI, 1.50 to $1.58 ; P<.001$ ) higher odds of having mild myopia, 2.45-fold (95\% CI, 2.37 to 2.53;
$P<.001)$ higher odds of having moderate myopia, and 2.73-fold (95\% CI, 2.58 to $2.88 ; P<.001$ ) higher odds of having high myopia.

Both the verbal and non-verbal components of the CFS had a consistent positive association with myopia in univariable regression models (eTable 2 in the Supplement). Following multivariable adjustment, the association with myopia in each of the subtests was further accentuated and remained consistent (Fig. 4). Markedly,

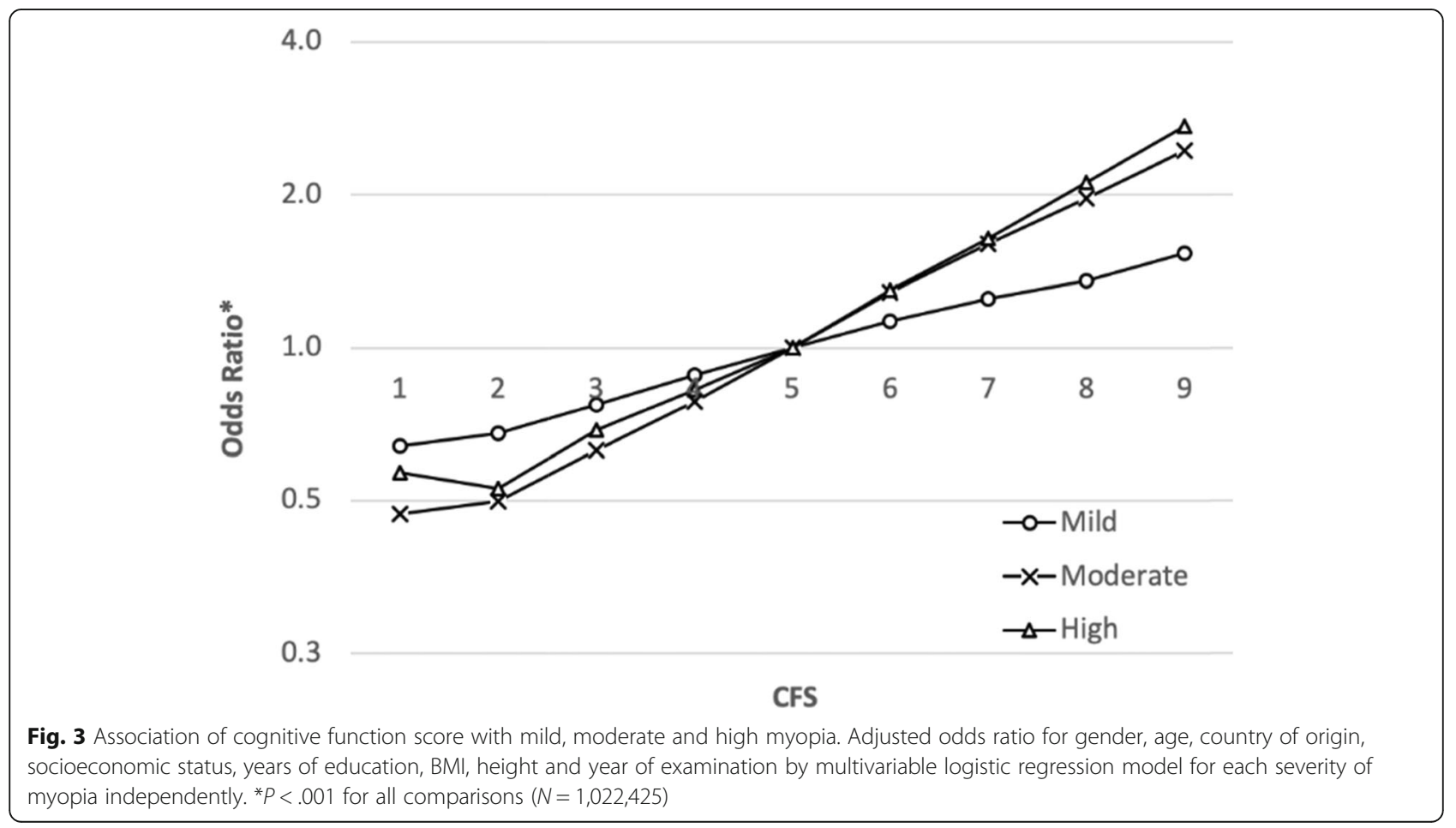




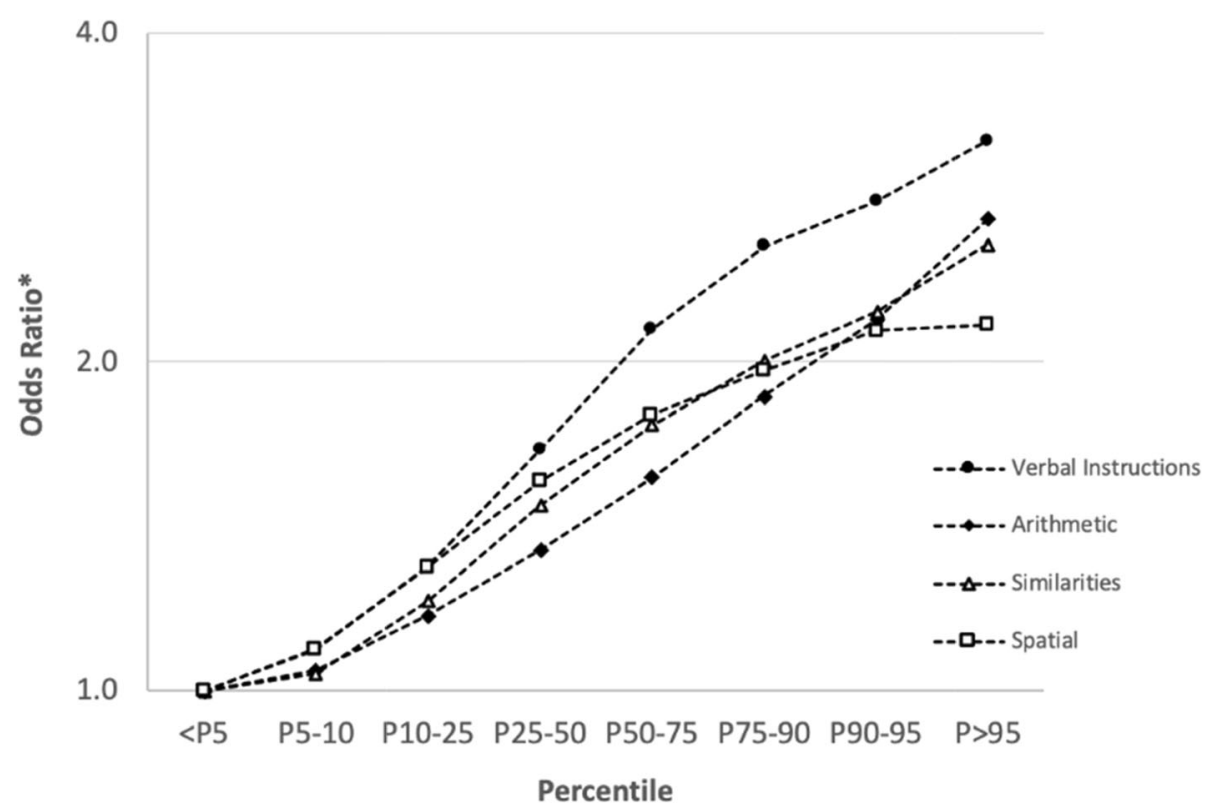

Fig. 4 Association of cognitive function subtests with myopia in multivariable models. Values represent the odds ratio for myopia in the 95th percentile group compared to the $<5$ th percentile group in each subtest. Adjusted odds ratio for gender, age, country of origin, socioeconomic status, years of education, BMI, height and year of examination by multivariable logistic regression model for each subtest independently. ${ }^{*} P<.001$ for all comparisons $(N=1,022,425)$

the verbal instructions subtest had the strongest association with myopia (OR, 3.19; $95 \% \mathrm{CI}, 3.10$ to $3.28 ; P<.001)$.

The consistent positive association found between CFS and myopia persisted in a series of sensitivity analyses, including a sex-specific analysis (eTable 3 in the Supplement), and an analysis modeling the association with stricter definition of myopia (SEQ $\leq-1.00$ diopter) (eFigure 1 in the Supplement). In our population, only 6.5\% had less than 12 years of education. In a stratified analysis by years of education, the association between CFS and myopia persisted across strata. The confidence interval was wide for those with lower years of education and high CFS, due to small number of participants (eTable 4).

\section{Discussion}

In this comprehensive study among 1,022,425 Israeli adolescents, we found cogent evidence that cognitive function is strongly and consistently associated with myopia, independent of age, gender, country of origin, socioeconomic status, years of education, body mass index, height and year of examination. Both the verbal and non-verbal components of the cognitive evaluation were associated with myopia.

Myopia is considered a multifactorial disorder that is affected by both hereditary and environmental factors [7-9]. Cognitive function was assumed to be one of the most arguable and investigated associations with myopia [10]. Several studies found a significantly positive association between cognitive function and myopia among children [28], Jewish-adolescent males [29], and among adults and the elderly $[13,30]$, while others found lack of statistically significant relationship [14-16]. In this study we found a positive, strong and independent association between cognitive function and myopia, which was consistent regardless of the severity of the myopia or the cognitive subtest.

The mechanism of the association between intelligence and myopia remains to be clarified [31]. One of the plausible explanations is a behavioral relationship between the two traits [32]. It was previously reported that subjects who read more or engage in educational activities have superior performance on intelligence tests, particularly those assessing verbal intelligence [33]. Additional works have shown that greater amount of nearwork activity such as reading increases the odds of having myopia [20,34]. Bez et al. [17] has recently reported a 9.3-fold increased odds of having myopia among ultraOrthodox Jewish students exposed to near-work activities from a very young age compared with age-matched secular students. Similarly, another study found significantly higher rates of myopia among Orthodox Jewish male students, emphasizing the effect that near-work activities have on the development of myopia [35]. This argument gains support from our finding that verbal intelligence tests, which require acquisition of linguistic skills mainly through reading, had stronger association with myopia than non-verbal intelligence tests. On the other hand, one can argue that the amount of reading is 
determined by the level of a person's intelligence, and therefore there is a predisposition among more intelligent children to develop myopia. This notion is countered by our finding of a statistically significant association between myopia and spatial intelligence, which was assessed by a modified version of Raven's Progressive Matrices [25]. This test, which examines visual-spatial problem solving abilities, does not rely on linguistic abilities or previously acquired information [36]. This finding also counters the argument by Young et al. that myopes have higher scores on intelligence tests because they are more capable of quick and efficient reading than emmetropes or hypermetropes [14, 37].

Another possible, yet unlikely explanation for the association between intelligence and myopia rests on a biological relationship, according to which myopia is an overdevelopment of the eye, and as ocular and cerebral development are related [31], this in turn leads to superior intelligence among myopes [38]. Some researchers suggested that there is a pleiotropic relationship between myopia and cognitive function, i.e. both traits are affected by the same gene or set of genes [12, 39, 40]. Several reviews covered the genes associated with myopia [41-43], but none addressed the association of these genes with cognitive development. More recent genomewide association studies found a modest but significant contribution of pleiotropic genetic factors contributing to the development of myopia and higher intelligence [44]. However, based on the current evidence, there are no genes that were proven to play a major role in the development of these traits.

This study has several limitations. First, a causal inference between cognitive function and myopia cannot be established from a cross-sectional design. Second, the database had no data on the refractive error of the subjects' parents, which might be relevant for the genetic component of myopia [45]. The rapid increase in myopia prevalence during the past several decades that was also observed in our analysis does, however, give weight to the crucial influence of environmental factors in the development of myopia. Third, our sample is not necessarily representing the Israeli female adolescent population, as approximately $30 \%$ of them are not recruited to the IDF mainly because of religious beliefs [46], therefore the association between cognitive function and myopia among the female population should be interpreted with more caution. Fourth, the non-cycloplegic refraction method used in this study, which results in a slight overestimation of myopia, especially among children and young adults [47], is less accurate than cycloplegic refraction. It was previously shown that non-cycloplegic refraction can overestimate the prevalence of myopia in populations up to the age of 50 and that cycloplegic refraction should be used in these age groups [48].
Nevertheless, using a stricter definition for myopia (SEQ $\leq-1.00$ diopter) reaffirms the main association found in this study (eFigure 1 in the Supplement). Our SES variable was crude as the classification was made according to the participants' settlements. This may explain the weak association found between SES and prevalence of myopia. Lastly, we included conscripts examined up to the year 2012 due to change in draft policy that included the enlistment of the ultra-Orthodox Jewish population, who have extremely high proportions of myopia (82\%) [17]. Future studies will analyze the association in newer cohorts.

\section{Conclusions}

In conclusion, we found cogent evidence of the association of cognitive function with myopia in more than one million Israeli adolescents. This finding was most pronounced for verbal intelligence subtests, which require acquisition of linguistic skills. Findings of our study point to the role of educational activity and intensive reading in the development of myopia. Further research is warranted to replicate these findings in other populations and study its mechanism.

\section{Supplementary information}

Supplementary information accompanies this paper at https://doi.org/10. 1186/s12889-020-08765-8.

Additional file 1: eTable 1. Myopia prevalence by year of examination, univariable logistic regression analysis. eTable 2. Cognitive function assessment subtests and association with myopia in univariable and multivariable models. eTable 3. Association of cognitive function score (CFS) with myopia among males and females in multivariable models. eTable 4. Association of cognitive function score (CFS) with myopia with stratification for years of education in multivariable models. eFigure $\mathbf{1}$. Sensitivity analysis of the association of cognitive function score (CFS) with stricter definition of myopia (<- 1.00 Diopter). Values represent the odds ratio for each CFS group in comparison with the intermediate CFS. Gray area represents the $95 \%$ confidence interval. $P<.001$ for all comparisons. Adjusted odds ratio for age, gender, country of origin, socioeconomic status, years of education, BMl, height and year of examination by multivariable logistic regression model. (CFS, cognitive function score).

\section{Abbreviations}

IDF: Israel Defense Forces; BCVA: Best-corrected visual acuity; SEQ: Spherical equivalent; CFS: Cognitive function score; BMI: Body mass index;

SES: Socioeconomic status; CDC: Center for Disease Control; OR: Odds ratio; $\mathrm{Cl}$ : Confidence interval

\section{Acknowledgements}

We thank Dorit Tzur, head of Information Branch of the IDF Medical Corps; Ron Kedem, statistical consultant; Raid Kayouf, medical research coordinator of the IDF Medical Corps; Dr. Haitam Saab for their help in data acquisition.

\section{Authors' contributions}

K.M., A.B. and H.L. contributed to the concept of the study. K.M. and D.B. acquired and analyzed the data. K.M., A.B., M.B. and H.L. helped with the interpretation of the data. K.M., M.B. and H.L. drafted the manuscript. A.B. and H.L. supervised the study. All authors read and approved the final manuscript. 


\section{Funding}

This research did not receive any specific grant from funding agencies in the public, commercial, or not-for-profit sectors.

\section{Availability of data and materials}

The datasets used and/or analysed during the current study are available from the corresponding author on reasonable request.

\section{Ethics approval and consent to participate}

This study was approved by the Institutional Ethics Committee of the Israel Defense Forces Medical Corps (Approval No. 1669-2016) and conformed to the tenets of the Declaration of Helsinki. Participants anonymity was preserved. Patient consent was waived as the raw data was deidentified.

\section{Consent for publication}

Not applicable.

\section{Competing interests}

A.B. reports receiving personal fees from Nanoretina and grants from Cellcure, Byonics, Novartis, and MicroSert outside the submitted work. The rest of the authors have no conflicts of interest to disclose.

\section{Author details}

${ }^{1}$ Medical Corps, Israel Defense Forces, Ramat-Gan, Israel. ${ }^{2}$ Hebrew University-Hadassah Faculty of Medicine, Braun School of Public Health and Community Medicine, P.O Box 12272, 9112002 Jerusalem, Israel. ${ }^{3}$ Department of Ophthalmology, Tel Aviv Sourasky Medical Center, Tel Aviv, Israel. ${ }^{4}$ Sackler Faculty of Medicine, Tel Aviv University, Tel Aviv, Israel.

Received: 3 January 2020 Accepted: 23 April 2020

Published online: 08 May 2020

\section{References}

1. Williams KM, Bertelsen G, Cumberland P, Wolfram C, Verhoeven VJ, Anastasopoulos E, Buitendijk GH, Cougnard-Gregoire A, Creuzot-Garcher C, Erke $M G$, et al. Increasing prevalence of myopia in Europe and the impact of education. Ophthalmology. 2015;122(7):1489-97.

2. Pascolini D, Mariotti SP. Global estimates of visual impairment: 2010. Br J Ophthalmol. 2012;96(5):614-8.

3. Pan CW, Ramamurthy D, Saw SM. Worldwide prevalence and risk factors for myopia. Ophthalmic Physiol Opt. 2012;32(1):3-16.

4. Morgan IG, French AN, Ashby RS, Guo X, Ding X, He M, Rose KA. The epidemics of myopia: Aetiology and prevention. Prog Retin Eye Res. 2018; 62:134-49.

5. Holden BA, Fricke TR, Wilson DA, Jong M, Naidoo KS, Sankaridurg P, Wong TY, Naduvilath TJ, Resnikoff S. Global prevalence of myopia and high myopia and temporal trends from 2000 through 2050. Ophthalmology. 2016;123(5):1036-42.

6. Saw SM, Gazzard G, Shih-Yen EC, Chua WH. Myopia and associated pathological complications. Ophthalmic Physiol Opt. 2005;25(5):381-91.

7. Chen CJ, Cohen BH, Diamond EL. Genetic and environmental effects on the development of myopia in Chinese twin children. Ophthalmic Paediatr Genet. 1985;6(1-2):353-9.

8. Saw SM, Hong CY, Chia KS, Stone RA, Tan D. Nearwork and myopia in young children. Lancet. 2001;357(9253):390.

9. Young TL, Metlapally R, Shay AE. Complex trait genetics of refractive error. Arch Ophthalmol. 2007;125(1):38-48.

10. Verma A, Verma A. A novel review of the evidence linking myopia and high intelligence. J Ophthalmol. 2015;2015:271746.

11. Czepita D, Lodygowska E, Czepita M. Are children with myopia more intelligent? A literature review. Ann Acad Med Stetin. 2008;54(1):13-6 discussion 16.

12. Cohn SJ, Cohn CM, Jensen AR. Myopia and intelligence: a pleiotropic relationship? Hum Genet. 1988;80(1):53-8.

13. Mirshahi A, Ponto KA, Laubert-Reh D, Rahm B, Lackner KJ, Binder H, Pfeiffer $\mathrm{N}$, Unterrainer JM. Myopia and cognitive performance: results from the Gutenberg health study. Invest Ophthalmol Vis Sci. 2016;57(13):5230-6.

14. Nadell MC, Hirsch MJ. The relationship between intelligence and the refractive state in a selected high school sample*. Optom Vis Sci. 1958;35(6): $321-6$.
15. Akrami A, Bakmohammadi N, Seyedabadi M, Nabipour I, Mirzaei Z, Farrokhi S, Assadi M. The association between schoolchildren intelligence and refractive error. Eur Rev Med Pharmacol Sci. 2012;16(7):908-11.

16. Dirani $M$, Zhang $X$, Goh LK, Young TL, Lee P, Saw SM. The role of vision in academic school performance. Ophthalmic Epidemiol. 2010;17(1):18-24.

17. Bez D, Megreli J, Bez M, Avramovich E, Barak A, Levine H. Association between type of educational system and prevalence and severity of myopia among male adolescents in Israel. JAMA Ophthalmol. 2019;137(8):887-93.

18. Twig G, Yaniv G, Levine H, Leiba A, Goldberger N, Derazne E, Ben-Ami Shor D, Tzur D, Afek A, Shamiss A, et al. Body-mass index in 2.3 million adolescents and cardiovascular death in adulthood. N Engl J Med. 2016; 374(25):2430-40.

19. Bar Dayan Y, Levin A, Morad Y, Grotto I, Ben-David R, Goldberg A, Onn E, Avni I, Levi Y, Benyamini OG. The changing prevalence of myopia in young adults: a 13-year series of population-based prevalence surveys. Invest Ophthalmol Vis Sci. 2005;46(8):2760-5.

20. Li SM, Li SY, Kang MT, Zhou Y, Liu LR, Li H, Wang YP, Zhan SY, Gopinath B, Mitchell P, et al. Near work related parameters and myopia in Chinese children: the Anyang childhood eye study. PLoS One. 2015;10(8):e0134514.

21. Kempen JH, Mitchell P, Lee KE, Tielsch JM, Broman AT, Taylor HR, Ikram MK, Congdon NG, O'Colmain BJ, Eye Diseases Prevalence Research G. The prevalence of refractive errors among adults in the United States, Western Europe, and Australia. Arch Ophthalmol. 2004;122(4):495-505.

22. Vitale S, Ellwein L, Cotch MF, Ferris FL 3rd, Sperduto R. Prevalence of refractive error in the United States, 1999-2004. Arch Ophthalmol. 2008; 126(8):1111-9.

23. Gal R. The selection, classification and placement process. In: A Portrait of the Israeli Soldier, pp. 77-96. Westport: Greenwood Press; 1986.

24. Davidson M, Reichenberg A, Rabinowitz J, Weiser M, Kaplan Z, Mark M. Behavioral and intellectual markers for schizophrenia in apparently healthy male adolescents. Am J Psychiatry. 1999;156(9):1328-35.

25. Rabinowitz J, Reichenberg A, Weiser M, Mark M, Kaplan Z, Davidson M. Cognitive and behavioural functioning in men with schizophrenia both before and shortly after first admission to hospital. Cross-sectional analysis. Br J Psychiatry. 2000;177:26-32.

26. Tzibel N. Characterization and Classification of Local Authorities by the Socio-economic Level of the Population in 2006. Hebrew: Central Bureau of Statistics; 2009

27. Kuczmarski RJ, Ogden CL, Guo SS, Grummer-Strawn LM, Flegal KM, Mei Z, Wei R, Curtin LR, Roche AF, Johnson CL. 2000 CDC growth charts for the United States: methods and development. Vital Health Stat 11. 2002;(246):1-190.

28. Saw SM, Tan SB, Fung D, Chia KS, Koh D, Tan DT, Stone RA. IQ and the association with myopia in children. Invest Ophthalmol Vis Sci. 2004;45(9): 2943-8.

29. Rosner M, Belkin M. Intelligence, education, and myopia in males. Arch Ophthalmol. 1987;105(11):1508-11.

30. Spierer O, Fischer N, Barak A, Belkin M. Correlation between vision and cognitive function in the elderly: a cross-sectional study. Medicine (Baltimore). 2016;95(3):e2423.

31. Hirsch MJ. The relationship between refractive state of the eye and intelligence test scores*. Optom Vis Sci. 1959;36(1):12-21.

32. Mutti DO, Mitchell GL, Moeschberger ML, Jones LA, Zadnik K. Parental myopia, near work, school achievement, and children's refractive error. Invest Ophthalmol Vis Sci. 2002;43(12):3633-40.

33. Ramsden S, Richardson FM, Josse G, Shakeshaft C, Seghier ML, Price CJ. The influence of reading ability on subsequent changes in verbal IQ in the teenage years(). Dev Cogn Neurosci. 2013;6:30-9.

34. Ip JM, Saw SM, Rose KA, Morgan IG, Kifley A, Wang JJ, Mitchell P. Role of near work in myopia: findings in a sample of Australian school children. Invest Ophthalmol Vis Sci. 2008;49(7):2903-10.

35. Zylbermann R, Landau D, Berson D. The influence of study habits on myopia in Jewish teenagers. J Pediatr Ophthalmol Strabismus. 1993;30(5): 319-22.

36. Burke HR. Raven's progressive matrices: a review and critical evaluation. J Genet Psychol. 1958;93(2):199-228.

37. Young FA. Reading, measures of intelligence and refractive errors. Am 」 Optom Arch Am Acad Optom. 1963;40:257-64.

38. Miller EM. On the correlation of myopia and intelligence. Genet Soc Gen Psychol Monogr. 1992;118(4):361-83.

39. Karlsson JL. Influence of the myopia gene on brain development. Clin Genet. 1975;8(5):314-8. 
40. Mak W, Kwan MWM, Cheng TS, Chan KH, Cheung RTF, Ho SL. Myopia as a latent phenotype of a pleiotropic gene positively selected for facilitating neurocognitive development, and the effects of environmental factors in its expression. Med Hypotheses. 2006;66(6):1209-15.

41. Baird PN, Schäche M, Dirani M. The GEnes in myopia (GEM) study in understanding the aetiology of refractive errors. Prog Retin Eye Res. 2010; 29(6):520-42.

42. Verhoeven VJ, Hysi PG, Wojciechowski R, Fan Q, Guggenheim JA, Hohn R, MacGregor S, Hewitt AW, Nag A, Cheng CY, et al. Genome-wide metaanalyses of multiancestry cohorts identify multiple new susceptibility loci for refractive error and myopia. Nat Genet. 2013;45(3):314-8.

43. Wojciechowski R, Hysi PG. Focusing in on the complex genetics of myopia. PLoS Genet. 2013;9(4):e1003442.

44. Williams KM, Hysi PG, Yonova-Doing E, Mahroo OA, Snieder H, Hammond CJ. Phenotypic and genotypic correlation between myopia and intelligence. Sci Rep. 2017;7:45977.

45. Goldschmidt E, Jacobsen N. Genetic and environmental effects on myopia development and progression. Eye. 2014;28(2):126-33.

46. Levine H, Leiba M, Bar Zeev Y, Keinan-Boker L, Derazne E, Leiba A, Kark JD. Risk of Hodgkin lymphoma according to immigration status and origin: a migrant cohort study of 2.3 million Jewish Israelis. Leuk Lymphoma. 2017; 58(4):959-68.

47. Sanfilippo PG, Chu BS, Bigault O, Kearns LS, Boon MY, Young TL, Hammond CJ, Hewitt AW, Mackey DA. What is the appropriate age cut-off for cycloplegia in refraction? Acta Ophthalmol. 2014;92(6):e458-62.

48. Morgan IG, Iribarren R, Fotouhi A, Grzybowski A. Cycloplegic refraction is the gold standard for epidemiological studies. Acta Ophthalmol. 2015;93(6):581-5.

\section{Publisher's Note}

Springer Nature remains neutral with regard to jurisdictional claims in published maps and institutional affiliations.

Ready to submit your research? Choose BMC and benefit from:

- fast, convenient online submission

- thorough peer review by experienced researchers in your field

- rapid publication on acceptance

- support for research data, including large and complex data types

- gold Open Access which fosters wider collaboration and increased citations

- maximum visibility for your research: over $100 \mathrm{M}$ website views per year

At $\mathrm{BMC}$, research is always in progress.

Learn more biomedcentral.com/submissions 